\title{
Avaliação das atividades antibacteriana, tripanocida e citotóxica do extrato hidroalcóolico das raízes de Tradescantia sillamontana Matuda (Veludo Branco) (Commelinaceae)
}

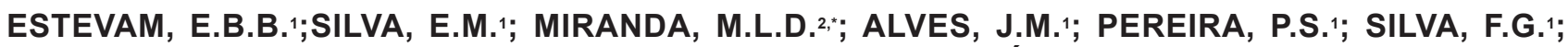
ESPERANDIM, V.R. ; MARTINS, C.H.G. ${ }^{3}$; AMBROSIO, M.A.L.V. $;$; TÓFOLI, D.4; JUNIOR, L.R.A.4; ALVES, C.C.F. 1

1'Instituto Federal de Educação, Ciência e Tecnologia Goiano, Câmpus Rio Verde, Rodovia Sul Goiana, km 01, Zona Rural, Caixa Postal 66, Rio Verde, GO, 75901-970, Brasil.2Instituto Federal de Educação, Ciência e Tecnologia do Sul de Minas Gerais - Câmpus Pouso Alegre, 37550-000, Pouso Alegre - MG, Brasil. ${ }^{3}$ Universidade de Franca, Laboratório de Pesquisa em Microbiologia Aplicada, LaPeMa - Avenida Dr. Armando

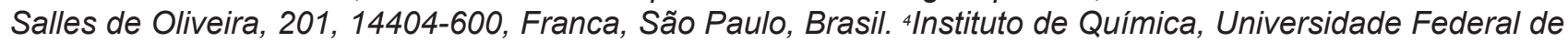
Mato Grosso do Sul, CP 549, 79070-900 Campo Grande - MS, Brasil. *Autor para correspondência: mayker. miranda@ifsuldeminas.edu.br

RESUMO: O objetivo deste estudo foi avaliar o efeito antibacteriano e tripanocida in vitro do extrato hidroalcóolico das raízes de Tradescantia sillamontana Matuda (Commelinaceae), conhecida popularmente como veludo branco. Foi avaliada a atividade antibacteriana in vitro frente às bactérias Streptococcus mitis (CIM $=100 \mu \mathrm{g} / \mathrm{mL} ; \mathrm{CMB}=150 \mu \mathrm{g} / \mathrm{mL}$ ), Streptococcus mutans $(\mathrm{CIM}=200 \mu \mathrm{g} / \mathrm{mL} ; \mathrm{CMB}=220 \mu \mathrm{g} / \mathrm{mL})$, Streptococcus sanguinis $(\mathrm{CIM}=400 \mu \mathrm{g} / \mathrm{mL}$; $\mathrm{CMB}=425 \mu \mathrm{g} / \mathrm{mL}$ ), Streptococcus sobrinus (CIM $=400 \mu \mathrm{g} / \mathrm{mL} ; \mathrm{CMB}=420 \mu \mathrm{g} / \mathrm{mL}$ ) e Bacteroides fragilis $(\mathrm{CIM}=400 \mu \mathrm{g} / \mathrm{mL} ; \mathrm{CMB}=430 \mu \mathrm{g} / \mathrm{mL}$ ) pelo método de diluição em caldo. Os protozoários da família tripanossomatídeo causam doenças tropicais que costumam ser negligenciadas que costumam ser como a tripanossomíase, para a qual estão disponíveis poucos medicamentos. Neste contexto, o extrato hidroalcóolico das raízes de $T$. sillamontana também foi avaliado frente às formas tripomastigotas da cepa $\mathrm{Y}$ de Trypanosoma cruzi, com promissora atividade frente a este protozoário $\left(\mathrm{IC}_{50}=2,4 \mu \mathrm{g} / \mathrm{mL}\right)$. Quando avaliada a atividade citotóxica frente a fibroblastos da linhagem $\mathrm{LLCMK}_{2}$, o extrato apresentou moderada citotoxicidade $\left(\mathrm{CC}_{50}=480,37\right.$ $\mu \mathrm{g} / \mathrm{mL}$ ). Os resultados ora apresentados para o extrato hidroalcóolico das raízes de Tradescantia sillamontana Matuda demonstraram promissoras atividades antibacteriana e tripanocida, sendo uma fonte alternativa de produtos naturais com atividades contra T. cruzi e algumas bactérias do gênero Streptococcus e Bacteroides.

Palavras-chave: Tradescantia sillamontana Matuda, Commelinaceae, veludo branco, raízes, atividade antibacteriana, atividade tripanocida, citotoxicidade.

\begin{abstract}
Evaluation of antibacterial, trypanocidal and cytotoxical activities of the hydroalcoholic extract from the roots of Tradescantia sillamontana Matuda (Veludo Branco) (Commelinaceae). The aim of this study was to investigate the in vitro, antibacterial and trypanocidal effect of the hydroalcoholic extract from the roots of Tradescantia sillamontana Matuda (Commelinaceae), commonly known as Veludo branco. The in vitro antibacterial activity against the standard bacteria Streptococcus mitis (MIC $=100 \mu \mathrm{g} / \mathrm{mL} ; \mathrm{MBC}=150 \mu \mathrm{g} /$ $\mathrm{mL}$ ), Streptococcus mutans (MIC $=200 \mu \mathrm{g} / \mathrm{mL} ; \mathrm{MBC}=220 \mu \mathrm{g} / \mathrm{mL}$ ), Streptococcus sanguinis $(\mathrm{MIC}=400 \mu \mathrm{g} / \mathrm{mL} ; \mathrm{MBC}=425 \mu \mathrm{g} / \mathrm{mL})$, Streptococcus sobrinus $(\mathrm{MIC}=400 \mu \mathrm{g} / \mathrm{mL} ; \mathrm{MBC}=420$ $\mu \mathrm{g} / \mathrm{mL}$ ) andBacteroides fragilis $(\mathrm{MIC}=400 \mu \mathrm{g} / \mathrm{mL} ; \mathrm{MBC}=430 \mu \mathrm{g} / \mathrm{mL})$, using microdilution broth methods. Protozoans from the trypanosomatid family cause neglected tropical diseases such as trypanosomiasis, for which few drugs are available. In this context, the hydroalcoholic extract of the Tradescantia sillamontana roots was also investigated with regards to the in vitro effects against the trypomastigote forms of theY strain of Trypanosoma cruzi, showing strong activity against this parasite $\left(\mathrm{IC}_{50}=2.4 \mu \mathrm{g} / \mathrm{mL}\right)$. When performing cytotoxic activity against fibroblasts $\mathrm{LLCMK}_{2}$ line, the extract showed moderate cytotoxicity $\left(\mathrm{CC}_{50}=480.37 \mathrm{mg} / \mathrm{mL}\right)$.
\end{abstract}

Recebido para publicação em - 09/11/2015

Aceito para publicação em - 08/04/2016

10.1590/1983-084X/15_215

Rev. Bras. PI. Med., Campinas, v.18, n.2, p.415-422, 2016. 
The results presented for the hydroalcoholic extract of the roots of Tradescantia sillamontana Matuda demonstrated effective antibacterial and trypanocidal activities and were shown to be an alternative source of natural products with activity against $T$. cruzi and some bacteria of the genus Streptococcus and Bacteroides.

Key words: Tradescantia sillamontana Matuda, Commelinaceae, veludo branco, roots, antibacterial activity, trypanocidal activity, cytotoxicity.

\section{INTRODUÇÃO}

A utilização de plantas medicinais ocorre desde a antiguidade e registros antigos têm demonstrado a sabedoria do homem quanto à utilização e aplicação destes produtos naturais (Junior et al., 2013). Segundo a OMS (1988), planta medicinal é todo e qualquer vegetal que possui, em um ou mais órgãos, substâncias que podem ser utilizadas com fins terapêuticos ou que sejam precursores de fármacos semissintéticos.

O uso das plantas foi restrito durante séculos a pequenas comunidades e grupos étnicos, correspondendo a seus únicos recursos terapêuticos, sendo que na última metade do século XX tornou-se uma prática mundialmente difundida. Mediante esta realidade, prevalece à necessidade de estudos taxonômicos e farmacológicos das plantas, buscando aquelas com atividade medicinal e como fonte de substâncias com potencial terapêutico (Giordani et al., 2015).

No Brasil, o uso de plantas medicinais tem recebido relevante destaque, fato devido ao crescimento da utilização destas plantas, que são fontes de substâncias ativas que provocam no organismo humano reações que levam a cura ou ao alívio da doença (Rosa et al., 2012). As plantas medicinais e seus compostos são fontes de medicamentos para várias enfermidades, porém muitas delas são utilizadas popularmente, ainda sem comprovação científica disponível. Deste modo, ao longo dos anos, estudos mostraram que determinadas plantas apresentavam substâncias potencialmente perigosas do ponto de vista científico, e estas pesquisas confirmaram que muitas delas possuíam propriedades agressivas. Por esta razão, as plantas devem ser utilizadas com cuidado, respeitando também seus riscos toxicológicos (Mariz et al., 2010).

É descrito na literatura vários trabalhos que demonstram a ação terapêutica de plantas medicinais, inclusive com uma planta do mesmo gênero em estudo, como é o caso da atividade antimicrobiana apresentada pela planta Tradescantia pallida (Taboquinha roxa), em pesquisa realizada com o extrato hidroalcóolico das folhas deste espécime (Silva et al., 2015).

Em estudo com 42 espécies de Tradescantia, os compostos predominantemente encontrados foram os flavonoides C-glicosídeos de apigenina e luteolina (Martínez et al., 1993). Sabe-se que os flavonoides podem atuar em processos de cicatrização, como antioxidantes, além de apresentarem atividade antimicrobiana o que pode justificar a atividade apresentada pelo extrato das raízes da planta em estudo (Oliveira et al., 2012). Algumas espécies pertencentes ao gênero Tradescantia também já foram alvos de pesquisas, em que foi analisado o desempenho fotossintético no contexto de suas adaptabilidades a diversas condições ambientais (Samoilova et al., 2011).

A família Commelinaceae possui aproximadamente 650 espécies e 40 gêneros dispersos em regiões temperadas e tropicais e no Brasil são encontradas 74 espécies, destas 37 endêmicas, acomodadas em 14 gêneros, sendo Tripogandra Raf., Commelina L., Tradescantia Ruppius ex L. e Dichorisandra J.C. Mikan os mais numerosos. As representantes desta família caracterizam-se, principalmente, pelos caules herbáceos, carnosos, e pelas flores de variadas cores (Tolke et al., 2011).

A planta Tradescantia sillamontana Matuda é conhecida por suas folhas carnosas, esbranquiçadas e de aspecto aveludado, conferindo a ela deste modo a denominação de veludo branco. O gênero Tradescantia é amplamente empregado na ornamentação em várias regiões do país devido ao cultivo e propagação facilitados, além de possuir alta resistência aos fatores climáticos e ambientais (Savóia, 2007). Na região Nordeste, plantas deste gênero são utilizadas no tratamento de reumatismo e dores nas articulações, sendo consumidas principalmente na forma de tinturas (Oliveira, 2008).

As doenças infecciosas ainda são uma das principais causas de morte no mundo, sendo de significativa importância o desenvolvimento de novos compostos antimicrobianos. Nesse aspecto, o estudo de extratos orgânicos pode ser uma boa alternativa na busca de compostos promissores que apresentem diversas atividades biológicas (Paula et al., 2015). As atividades antimicrobianas dependem destes compostos promissores que podem apresentar ação contra bactérias Grampositivas e Gram-negativas, podendo atuar também sobre leveduras, fungos e parasitas (Bertini et al., 
2005; Ushimaru et al., 2007; Viegas et al., 2000; Miranda et al., 2013).

Derivados de plantas como extratos vegetais, óleos essenciais, e compostos puros, já foram avaliados em relação aos seus efeitos antimicrobianos contra agentes patogênicos orais como Streptococcus mitis, Streptococcus mutans, Streptococcus sanguinis e Streptococcus sobrinus, bactérias estas que estão sendo avaliadas neste trabalho. Estes derivados têm atraído o interesse de grupos de pesquisa, uma vez que podem ser empregues no desenvolvimento de novas soluções para enxague bucal utilizado na higiene oral. No entanto, relatos sobre a atividade antimicrobiana de produtos naturais contra patógenos bucais ainda são escassos (Moreira et al., 2014). Outra bactéria foco deste trabalho é pertencente ao gênero Bacteroides, à espécie $B$. fragilis avaliada apesar de minoritária na microbiota intestinal, é a mais frequentemente associada a processos infecciosos, tais como bacteremias, infecções intra-abdominais, abscessos e infecções em tecidos moles (Nakano et al., 2004).

As doenças tropicais negligenciadas são um grupo de 13 doenças consideradas infecções crônicas comuns em pessoas mais carentes, oriundas de países menos desenvolvidos (Ferreira et al., 2012). Destaca-se desta forma, a doença de Chagas, que é causada pelo protozoário Trypanosoma cruzi pertencente à família Trypanosomatidae e à ordem Kinetoplastida, no qual seu ciclo de vida envolve obrigatoriamente a passagem por um hospedeiro intermediário - Triatoma infestans (barbeiro) para um definitivo, passando por uma série de estágios. Apresenta flagelo (epimastigota e tripomastigota) ou aflagelado (amastigota) dependendo do hospedeiro. Por conta do considerado fluxo de pessoas em países como Estados Unidos, Canadá e Europa, a doença vem ganhando espaço e tem se tornado problema sério, nesses países (Carneiro et al., 2015).

Atualmente, a quimioterapia é o único tratamento específico disponível para esta doença, onde os medicamentos utilizados são nifurtimox e benzonidazol (Rassi et al., 2010; Santos et al., 2012). Estas drogas podem curar com êxito, aproximadamente, $20 \%$ a $80 \%$ de pacientes com doença de Chagas aguda, porém existem reações adversas como anorexia, náuseas, desordens psicológicas, polineuropatias e dermatitis, advindas do uso destas drogas (Rodrigues et al., 2014). Desta forma, devido às limitações dos medicamentos disponíveis para o tratamento da Doença de Chagas e os inúmeros efeitos colaterais por eles demonstrados, vê-se a necessidade de investigação de novos princípios ativos, mais eficazes e menos tóxicos.

Frente a esta problemática, o objetivo do presente trabalho foi avaliar o potencial citotóxico, antibacteriano e tripanocida in vitro do extrato hidroalcóolico das raízes de Tradescantia sillamontana Matuda.

\section{MATERIAL E MÉTODOS}

\section{Amostra vegetal}

As raízes do espécime estudado foram coletadas em julho de 2015 no município de Rio Verde - GO e sua identificação botânica foi realizada pelo Prof. Dr. V. Davi (DB/IFGOIANO), sendo uma exsicata $\left(n^{\circ} 875\right)$ incorporada ao Herbário Jataiense Professor Germano Guarin Neto.

\section{Preparação do extrato}

O extrato bruto hidroalcóolico das raízes de $T$. sillamontana foi obtido pelo processo de extração de $1,0 \mathrm{~kg}$ de raízes previamente limpas e trituradas em moinho de facas (Marconi®). As raízes moídas foram colocadas em um balão de fundo chato de $6 \mathrm{~L}$ e adicionou-se em seguida o solvente extrator, utilizando uma mistura de etanol:água (7:3). O processo de extração teve duração de duas semanas e a solução extraída foi filtrada em papel de filtro e concentrada em rotaevaporador (Janke e Kunkel( $\left.{ }^{\circledR}\right)$. A secagem total do extrato foi realizada em liofilizador da marca Savant Instruments INC., modelo Micro Modulyo dando origem ao extrato bruto hidroalcóolico (159,0 g).

\section{Cepas bacterianas}

As cepas testadas foram obtidas junto a American Type Culture Collection (ATCC, RockvilleMD, EUA). Os micro-organismos usados na avaliação da atividade antibacteriana do extrato bruto hidroalcóolico das raízes de $T$. sillamontana foram: Streptococcus mitis (ATCC 49456), Streptococcus mutans (ATCC 25175), Streptococcus sanguinis (ATCC 10556), Streptococcus sobrinus (ATCC 33478) e Bacteroides fragilis (ATCC 25285).

\section{Atividade antibacteriana (concentração inibitória mínima) \\ Os valores de concentração inibitória} mínima (CIM) do extrato bruto hidroalcóolico de raízes de $T$. sillamontana foram determinados em triplicata pelo método de microdiluição, em microplacas com 96 poços (TPP, EUA) (Rios et al., 2005). As amostras foram dissolvidas em dimetilsulfóxido (DMSO, Synth, São Paulo, Brasil; $8000 \mu \mathrm{g} / \mathrm{mL}$ ), seguido da diluição em caldo de soja tríptica (Difco, Detroit, MI, EUA) para bactérias aeróbias e Schaedler Caldo (Difco), suplementado com hemina $(5,0 \mu \mathrm{g} / \mathrm{mL})$ e vitamina $\mathrm{K}(10,0 \mu \mathrm{g} / \mathrm{mL})$ para as bactérias anaeróbias, com a finalidade de

Rev. Bras. PI. Med., Campinas, v.18, n.2, p.415-422, 2016. 
atingir concentrações variando de 400 a $12,5 \mu \mathrm{g} /$ $\mathrm{mL}$. A concentração de DMSO (Sigma®) final foi de $4 \%$ (v/v), e esta solução foi usada como controle negativo. O inóculo foi ajustado para cada organismo a fim se obter uma concentração de células de $5 \times 10^{5}$ unidades formadoras de colônias por $\mathrm{mL}$, de acordo com o National Committee for Clinical Laboratory Standard (NCCLS) (NCCLS, 2003). O dicloridrato de clorexidina (DCC, Sigma, Poole, Dorset, Reino Unido) foi utilizado como controle positivo, e as concentrações variaram de $0,0115 \mu \mathrm{g} / \mathrm{mL}$ a $5,9 \mu \mathrm{g} /$ $\mathrm{mL}$. Foram realizados os controles de esterilidade dos caldos TSB e SCHAEDLER, esterilidade do dicloridrato de clorexidina, esterilidade da amostra, controle da cultura (inóculo) e o controle do DMSO. As microplacas (96 poços) com os micro-organismos aeróbios foram fechados com um vedante de placa estéril e incubados aerobicamente a $37^{\circ} \mathrm{C}$ durante $24 \mathrm{~h}$. Os micro-organismos anaeróbios foram fechados com um vedante de placa estéril e incubados de 48 a 72 horas numa câmara anaeróbia (Don Whitley Scientific, Bradford, Reino Unido), com $5 \%$ a $10 \%$ de $\mathrm{H}_{2}, 10 \%$ de $\mathrm{CO}_{2}, 80 \%$ a $85 \%$ de $\mathrm{N}_{2}$, a $37{ }^{\circ} \mathrm{C}$. Logo depois, resazurina (Sigma, $30 \mu \mathrm{L}$ ) em solução aquosa $(0,01 \%)$ foi adicionada para indicar viabilidade de micro-organismos. Os valores de CIM foram determinados a partir da concentração mais baixa do extrato bruto, capaz de inibir o crescimento de micro-organismos.

\section{Atividade antibacteriana (Concentração Mínima Bactericida) \\ Para a determinação da Concentração} Mínima Bactericida (CMB), cada alíquota da amostra foi inoculada em placas BHI Agar (MERCK ${ }^{\circledR}$ ) e posteriormente incubada em estufa bacteriológica a $37^{\circ} \mathrm{C} / 24 \mathrm{~h}$. A CMB é a menor concentração do extrato onde não houver crescimento bacteriano, ou seja, onde houve $99,9 \%$ de morte bacteriana (Duarte et al., 2003).

\section{Parasitas}

Foi utilizada a cepa Y de Trypanosoma cruzi, constituídas por formas tripomastigotas delgadas (Nussenzweig et al., 1953). Esta cepa vem sendo mantida no Biotério da Universidade de Franca, através de repiques sucessivos em camundongos Swiss, por punção cardíaca no dia do pico parasitêmico ( $7^{\circ}$ dia da infecção). Procedimento aprovado pelo Conselho Nacional de Controle de Experimentação Animal do Comitê de Ética da Universidade de Franca sob o protocolo número 010/14.

\footnotetext{
Avaliação da atividade tripanocida in vitro com sangue infectado

O ensaio foi realizado utilizando-se sangue
}

de camundongos albinos infectados, obtido por punção cardíaca no pico parasitêmico $\left(7^{\circ}\right.$ dia da infecção). O sangue infectado foi diluído com solução fisiológica de forma a se obter uma concentração final de sangue com $10^{6}$ formas tripomastigotas $/ \mathrm{mL}$.

As amostras a serem avaliadas foram diluídas em DMSO (Sigma®) e alíquotas desta solução estoque foram adicionadas ao sangue infectado na placa de microtitulação (96 poços), totalizando um volume de $200 \mu \mathrm{L}$.

Para a realização do ensaio tripanocida, as amostras foram avaliadas em triplicata nas concentrações de 200, 100, 50, 25, $12,5 \mu \mathrm{g} / \mathrm{mL}$. Como controles foram utilizados: (1) Controle positivo: benzonidazol (LAFEPE Medicamentos); (2) Controle negativo: $0,5 \%$ de DMSO (Sigma ${ }^{\circledR}$ ).

A microplaca foi incubada a $4^{\circ} \mathrm{C}$ por 24 e 48 horas, sendo que após este período, a atividade foi verificada quantitativamente, através da contagem das formas tripomastigotas, de acordo com a técnica empregada por Brenner (1962) e a determinação da porcentagem de lise parasitária foi realizada através da comparação com o grupo de controle sem tratamento.

\section{Avaliação da atividade citotóxica}

Fibroblastos da linhagem LLCMK ${ }_{2}$ foram cultivados em meio Roswell Park Memorial Institute (RPMI-Gibco) 1640, suplementado com 10\% de soro bovino fetal inativado ( $100 \mathrm{~mL}$ de soro) com $2,5 \mathrm{~mL}$ de estreptomicina e $2,5 \mathrm{~mL}$ de penicilina, em garrafas de cultura a $37^{\circ} \mathrm{C}$ em ambiente a $5 \%$ de $\mathrm{CO}_{2}$, com umidade de $95 \%$. O meio de cultura com as células foi transferido para um tubo fálcon estéril e centrifugado $\left(1500 \mathrm{rpm}\right.$ a $4^{\circ} \mathrm{C}$ por 15 minutos). Após a centrifugação o sobrenadante foi descartado e acrescentado $1 \mathrm{~mL}$ de RPMI para atingir a concentração final de $10^{6}$. Foi realizado um novo cultivo por 24 horas em estufa de $\mathrm{CO}_{2}$, e em seguida foi feito a leitura das placas em leitor de ELISA a 517 $\mathrm{nm}$, através da técnica colorimétrica pelo MTT.

Para a realização do ensaio de citotoxicidade, as amostras foram avaliadas nas concentrações de 400, 200, 100, 50, 25, 12.5 e $6.25 \mu \mathrm{g} / \mathrm{mL}$ em triplicata. Como controle positivo foi utilizado DMSO 25\% (Sigma ${ }^{\circledR}$ ) e controle negativo DMSO (Sigma ${ }^{\oplus}$ ) a 0,5\%.

Os ensaios foram realizados em triplicado, e o os resultados foram expressos como $\mathrm{CC}_{50}$, calculada pela estatística sigmoide, método de curva de concentração-resposta utilizando o GraphPad Prism (GraphPad Software Corporation, versão 5.0).

\section{RESULTADOS E DISCUSSÃO}

A atividade antibacteriana (CIM e CMB) do extrato bruto hidroalcóolico de raízes de $T$.

Rev. Bras. PI. Med., Campinas, v.18, n.2, p.415-422, 2016. 
sillamontana foi avaliada frente a algumas bactérias, como apresentada na tabela 1.

O extrato bruto estudado apresentou moderada atividade inibitória frente a todas as bactérias testadas demonstrando seu potencial como bactericida natural. Valores de CIM inferior a $100 \mu \mathrm{g} / \mathrm{mL}$ tem atividade antibacteriana considerada boa; de 100 a $500 \mu \mathrm{g} / \mathrm{mL}$ moderada; de 500 a 1000 $\mu \mathrm{g} / \mathrm{mL}$ fraca e acima de $1000 \mu \mathrm{g} / \mathrm{mL}$ inativa (Holetz et al., 2002; Ayres et al., 2008; Sousa et al., 2015).

De acordo com a tabela 1, verificou-se atividade inibitória em menores concentrações contra as bactérias Streptococcus mutans ATCC 25175 e Streptococcus mitis ATCC 49456. Estes resultados são interessantes, particularmente aquelas relativas à inibição do crescimento de S. mitis e S. mutans. S. Sanguinis e S. Sobrinus, bactérias pertencentes a um grupo de microorganismos causadores da cárie dentária para os quais são conhecidos alguns inibidores naturais (Moreira et al., 2014). O extrato bruto hidroalcóolico das raízes de $T$. sillamontana apresentou promissora atividade na menor concentração de $100 \mu \mathrm{g} / \mathrm{mL}$ frente à Streptococcus mutans (Tabela 1). S. mutans é o principal micro-organismo da cavidade oral e desempenha papel preponderante na formação de placas dentárias sendo considerado agente etiológico primário da cárie (Samarão et al., 2010).

Streptococcus mitis, Streptococcus mutans, Streptococcus sanguinis e Streptococcus sobrinus apresentam patogenicidade frente ao esmalte dos dentes e tecido gengival estando diretamente ligadas a cárie e doenças periodentais. A placa bacteriana tem sido definida como um biofilme de micro-organismos, contidos em matriz orgânica formada por substâncias da saliva e da dieta do hospedeiro e por polímeros bacterianos (Pereira et al., 2006).
O extrato hidroalcóolico das raízes de $T$. sillamontana apresentou ainda moderada atividade frente a outro gênero de bactérias Gram negativas, o Bacteroides fragilis na concentração de $400 \mu \mathrm{g} /$ $\mathrm{mL}$ (Tabela 1).

Bacteroides é um gênero bacteriano composto por bastonetes Gram negativos, não esporulados, anaeróbios estritos. A espécie $B$. fragilis é componente da microbiota intestinal, beneficiando seus hospedeiros, já que fisicamente excluem os patógenos em potencial de colonizar o intestino. Além disso, tal espécie é considerada patógeno oportunista em humanos, com a capacidade de causar infecções na cavidade peritoneal e levar à formação de abscessos quando ocorre um trauma, por exemplo, no sítio de colonização. A espécie $B$. fragilis apesar de minoritária na microbiota intestinal, é a mais frequentemente associada a processos infecciosos, tais como bacteremias, infecções intraabdominais, abscessos e infecções em tecidos moles (Nakano et al., 2004).

O extrato bruto hidroalcóolico das raízes de $T$. sillamontana apresentou promissora atividade tripanocida quando testado frente às formas tripomastigotas de T. cruzi. Observou-se a inviabilidade de células tripomastigotas com o aumento da concentração do extrato bruto, sendo a promissora atividade obtida com $\mathrm{IC}_{50}$ de $2,4 \mu \mathrm{g} / \mathrm{mL}$, melhor que o próprio padrão utilizado (benzonidazol: $\mathrm{IC}_{50}=9,8 \mu \mathrm{g} / \mathrm{mL}$ ) (Tabela 2).

A atividade tripanocida do extrato hidroalcóolico das raízes de $T$. sillamontana foi avaliada in vitro nas concentrações de $12.5,25$, 50,100 e $200 \mu \mathrm{g} / \mathrm{mL}$ sobre a forma tripomastigota, correspondentes à fase aguda da doença de Chagas. O extrato avaliado foi classificado como altamente ativo $\left(\mathrm{IC}_{50}<10 \mu \mathrm{g} / \mathrm{mL}\right)$ pelos critérios estabelecidos por Osorio et al., (2007).

TABELA 1. Efeito inibidor do extrato bruto hidroalcóolico de raízes de $T$. sillamontana frente a bactérias aeróbias e anaeróbias.

\begin{tabular}{|c|c|c|c|c|}
\hline & Micro-organismos & $\begin{array}{l}\text { Concentração Inibitória } \\
\text { Mínima }(\mathrm{CIM})-\mu \mathrm{g} / \mathrm{mL}\end{array}$ & $\begin{array}{c}\text { Concentração Mínima } \\
\text { Bactericida }(\mathrm{CMB})-\mu \mathrm{g} / \mathrm{mL}\end{array}$ & $\begin{array}{l}\text { Dicloridrato de clorexidina } \\
-\mu \mathrm{g} / \mathrm{mL} \text { (controle positivo) }\end{array}$ \\
\hline & Streptococcus mutans & 100 & 150 & 0,922 \\
\hline & (ATCC 25175) & & & \\
\hline \multirow{5}{*}{ Aeróbios } & Streptococcus mitisa & 200 & 220 & 1,844 \\
\hline & (ATCC 49456) & & & \\
\hline & Streptococcus sanguinisa & 400 & 425 & 0,922 \\
\hline & (ATCC 10556) & & & \\
\hline & Streptococcus sobrinusa & 400 & 420 & 0,922 \\
\hline \multirow{3}{*}{ Anaeróbio } & (ATCC 33478) & & & \\
\hline & Bacteroides fragilis ${ }^{b}$ & 400 & 430 & 0,737 \\
\hline & (ATCC 25285) & & & \\
\hline
\end{tabular}

aBactéria gram-positiva (aeróbia); ’Bactéria gram-negativa (anaeróbia) 
TABELA 2. Atividade tripanocida do extrato bruto hidroalcóolico das raízes de Tradescantia sillamontana frente à forma tripomastigota de $T$. cruzi.

\begin{tabular}{ccccccc}
\hline Extrato & \multicolumn{5}{c}{$\%$ de lise \pm D.P./concentração $(\mu \mathrm{g} / \mathrm{mL})$} \\
\cline { 2 - 6 } & 200 & 100 & 50 & 25 & 12,5 & $\mathrm{IC}_{50}(\mu \mathrm{g} / \mathrm{mL})$ \\
\hline EBHTS & $100 \pm 0$ & $93,87 \pm 4,0$ & $89,11 \pm 3,1$ & $85,71 \pm 5,3$ & $78,23 \pm 2,2$ & 2,4 \\
\hline aBHTS $=$ Extrato bruto hidroalcóolico de & T. sillamontana (raiz). Controle negativo: DMSO 0,5\%; Controle positivo: DMSO $25 \%$.
\end{tabular}

A atividade tripanocida do extrato bruto hidroalcóolico de T. sillamontana é descrita pela primeira vez neste trabalho. Em trabalhos já reportados, pode-se constatar a potencialidade de extratos de outras espécies vegetais do Cerrado, que apresentaram atividade tripanocida frente ao T. cruzi (in vivo). Como relatado por Herzog-Soares et al., (2006) em seus estudos com os extratos da casca do caule de Stryphnodendron adstringens e Stryphnodendron polyphyllum, foi observado o aumento da atividade tripanocida in vivo no sexto e oitavo dias, ocorrendo maior inibição de crescimento no oitavo dia, quando comparado ao grupo controle. Quando avaliado o extrato bruto das cascas do caule de Caryocar brasiliense, este apresentou atividade tripanocida com inibição de crescimento apenas no oitavo dia. Os resultados demonstraram que os extratos destas plantas encontradas no Cerrado apresentaram uma promissora atividade para o $T$. cruzi, assim como observado para o extrato das raízes de Tradescantia sillamontana. O extrato dos frutos de Ocotea paranapiacabensis revelou melhor atividade tripanocida que os outros extratos avaliados por Alves et al., (2012), apresentando o menor valor de $\mathrm{IC}_{50}=26,93 \mu \mathrm{g} / \mathrm{mL}$, sendo que este valor é ainda bastante superior ao encontrado para o extrato hidroalcóolico das raízes de T. sillamontana $\left(\mathrm{IC}_{50}=2,4 \mu \mathrm{g} / \mathrm{mL}\right)$, o que demonstra que o extrato da planta veludo branco apresenta alta atividade tripanocida.

A fração hexânica das folhas de Piper arboreum apresentou atividade semelhante aos resultados obtidos para o espécime alvo neste estudo. $O$ extrato etanólico de $P$. arboreum foi avaliado frente a linhagens de Trypanosoma cruzi, porém a fase hexânica foi a que apresentou melhor resultado com a morte de $62 \%$ e $51 \%$ de células epimastigotas e de $100 \%$ e $92 \%$ de células promastigotas (Figueredo et al., 2014). Extratos brutos hidroalcóolicos das folhas, casca, semente e caule de Passiflora cincinnata tiveram suas atividades antiparasitárias testadas frente ao Trypanosoma cruzi, não apresentando atividades relevantes (Delmondes et al., 2014). Quando avaliado o extrato vegetal de Mentha arvensis, o mesmo apresentou atividade anti-trypanosoma. Como avaliado para o extrato de $T$. sillamontana, o extrato etanólico das folhas de $M$. arvensis foi preparado para testes in vitro frente ao $T$. cruzi e quando testado demonstrou promissora atividade contra as cepas, apresentando 65 e 47\% de inibição em uma concentração de 500 $\mu \mathrm{g} / \mathrm{mL}$ (respectivamente, $C_{50}=192,3$ e $531,9 \mu \mathrm{g} /$ $\mathrm{mL}$ ) (Santos et al., 2012). Vários outros trabalhos envolvendo o estudo de extratos de plantas têmse revelado como uma alternativa na procura por compostos com potencial contra T. cruzi, como por exemplo, o extrato das folhas de Arrabidaea triplinervia, do qual isolou-se os triterpenos ácido ursólico e oleanólico que apresentam atividade tripanocida já reportada frente a forma tripomastigota do parasita (Leite et al., 2006). A partir do extrato da planta Dracocephalum kotschyi foram obtidos metabólitos potencialmente ativos contra a forma epimastigotas de Trypanosoma cruzi (Saeidnia et al., 2004). Para complementar a relevância dos estudos envolvendo extratos vegetais com atividade tripanocida, pode-se citar também o trabalho realizado com a planta Azorella compacta, através do qual foram obtidos diterpenoides ativos frente à forma amastigota intracelular do T. cruzi (Araya et al., 2003).

Estes estudos envolvendo extratos vegetais com a finalidade de se averiguar sua possível atividade tripanocida retrata a importância dos esforços para promover o uso sustentável da biodiversidade brasileira, centrando-se na pesquisa de novos agentes terapêuticos para o tratamento de algumas doenças negligenciadas que afetam milhões de pessoas no Brasil e em outros países.

A avaliação da citotoxidade em fibroblastos, pelo método colorimétrico do MTT mostrou que o extrato hidroalcóolico das raízes de $T$. sillamontana apresenta moderada citotoxidade, com $\mathrm{CC}_{50}=$ $480,37 \mu \mathrm{g} / \mathrm{mL}$ (Tabela 3 ) valor maior que o controle positivo utilizado, o benzonidazol $\left(\mathrm{CC}_{50}=147,37 \mu \mathrm{g} /\right.$ $\mathrm{mL}$ ). Segundo Andrade (2013) quanto menor o valor do $\mathrm{CC}_{50}$ mais citotóxico é o composto avaliado frente à linhagem celular utilizada.

A citotoxicidade foi realizada com as células $\mathrm{LLCMK}_{2}$ por ser o meio celular na qual são cultivados os parasitas em análise. Justifica-se a execução deste ensaio uma vez que se comprova a eficácia da amostra contra os parasitas sem que a mesma esteja lisando as células ao mesmo tempo em que lisa os parasitas.

O extrato das raízes de $T$. sillamontana foi classificado como moderadamente citotóxico $\left(\mathrm{CC}_{50}\right.$ $>100<1000 \mu \mathrm{g} / \mathrm{mL}$ ) em comparação com dados

Rev. Bras. PI. Med., Campinas, v.18, n.2, p.415-422, 2016. 
TABELA 3. Atividade citotóxica do extrato hidroalcóolico das raízes de $T$. sillamontana sobre fibroblastos

\begin{tabular}{|c|c|c|c|c|c|c|c|c|}
\hline \multirow[t]{2}{*}{ Extrato } & \multicolumn{8}{|c|}{$\%$ células viáveis $\pm D . P . / c o n c e n t r a c ̧ a ̃ o ~(\mu g / m L)$} \\
\hline & 6,25 & 12,5 & 25 & 50 & 100 & 200 & 400 & $\mathrm{CC}_{50}(\mu \mathrm{g} / \mathrm{mL})$ \\
\hline T. sillamontana & $100 \pm 0$ & $100 \pm 0$ & $100 \pm 0$ & $100 \pm 0$ & $100 \pm 0$ & $100 \pm 0$ & $90,7 \pm 1,7$ & 480,37 \\
\hline Benzonidazol & & & & & 147 & & & \\
\hline
\end{tabular}

já reportados por Alves et al. (2012) para o extrato de Ocotea indecora que apresentou valor de $\mathrm{CC}_{50}$ $=498,2 \mu \mathrm{g} / \mathrm{mL}$. Esta moderada citoxicidade do extrato é um indicador de que a planta pode ser bem tolerada frente ao sistema biológico. Entretanto, estudos mais detalhados para a avaliação da toxicidade do extrato bioativo empregando-se outros modelos (in vivo) se fazem necessários.

Os resultados do presente trabalho são promissores, visto que o extrato vegetal estudado demonstrou atividade antibacteriana frente a algumas bactérias do gênero Streptoccocus e Bacteroides, atividade tripanocida frente à forma tripomastigota do Trypanosoma cruzi além de apresentar-se moderadamente tóxico para as células $\mathrm{LLCMK}_{2}$, o que motiva estudos subsequentes para o isolamento e identificação dos princípios ativos responsáveis por estas atividades, com potencial de uso na indústria farmacêutica.

\section{REFERÊNCIAS}

ALVES, R.T. et al. Trypanocidal activity of Brasilian plant against epimastigote forms from $Y$ and Bolivia strains of Trypanosoma cruzi. Revista Brasileira de Farmacognosia, v. 22, n. 3, p. 528-533, 2012.

ANDRADE, M. A. Óleos essenciais de Cinnamodendron dinisii Schwacke e Siparuna guianensis Aublet: composição química, caracterização das estruturas secretoras e avaliação do potencial biológico. 2013. 227p. Tese (Área de concentração: Agroquímica) Curso de Pós Graduação em Agroquímica, Universidade Federal de Lavras, Lavras - MG.

ARAYA, J.E. et al. Diterpenoids from Azorella compacta (Umbelliferae) active on Trypanosoma cruzi. Memórias do Instituto Oswaldo Cruz, v.98, p.413-418, 2003.

AYRES, M.C.C. et al. Atividade antibacteriana de plantas úteis e constituintes químicos da raiz de Copernicia prunifera. Revista Brasileira de Farmacognosia, v.18, n.1, p.90-97, 2008.

BERTINI, L.M. et al. Perfil de sensibilidade de bactérias frente a óleos essenciais de algumas plantas do nordeste do Brasil. Revista Infarma, v.17, n.314, p.803, 2005.

BRENNER Z. Therapeutic activity and criterion of cure on mice experimentally infected with Trypanosoma cruzi. Revista do Instituto de Medicina Tropical de São Paulo, v.4, p. 389-396,1962.

CARNEIRO, J.N.P. et al., Avaliação da atividade tripanocida, leishmanicida e citotóxica do geraniol e citronelal. Caderno de Cultura e Ciência, v. 13, n. 2, p. 29-36, 2015.

DELMONDES, G.A. et al. Avaliação da citotoxicidade e atividade leishmanicida e tripanocida de extratos de Passiflora cincinnata Mast L. Caderno de Cultura e Ciência, v.13, n.1, p.31-38, 2014.

DUARTE, S. et al. Effect of a novel type of propolis and its chemical fractions on glucosyltransferases and on growth and adherence of mutans streptococci. Biological \& Pharmaceutical Bulletin. v.26, n.4, p. 527-31, 2003.

FERREIRA, E.I. et al. Planejamento de fármacos na área de doenças de chagas: Avanços e Desafios. Revista Virtual de Química, v. 4, n. 3, p. 225-246, 2012.

FIGUEREDO, F.G. et al. Avaliação das potenciais atividades tripanocida e antileishmania do extrato de folhas de Piper arboreum (Piperaceae) e de suas frações. Revista de Ciências Farmacêuticas Básica e Aplicada, v.35, n.1, p.149-154, 2014.

GIORDANI, C. et al. Levantamento de extratos vegetais com ação anti-Candida no período de 2005-2013. Revista Brasileira de Plantas Medicinais, v. 17, n. 1, p. 175-185, 2015.

HERZOG-SOARES, J.D.A. et al. Bioatividade de Stryphnodendron adstringens, S. polyphyllum, Caryocar brasiliense, plantas do Cerrado brasileiro, sobre Trypanosoma cruzi "in vivo". Bioscience Journal, v.12, n.3, p.113-118, 2006.

HOLETZ, F.B. et al. Screening of some plants used in the Brasilian folk medicine for the treatment of infectious diseases. Memórias do Instituto Oswaldo Cruz, v.97, n.7, p.1027-1031, 2002.

JUNIOR, L.R.A. et al. Pregnanos e outros constituintes das raízes de Macrosiphonia petraea (A. St.-Hill.) Kuntze (Apocynaceae). Química Nova, v.36, n. 4, p. 519-523, 2013.

LEITE, J.P.V. et al.Trypanocidal activity of Triterpenes from Arrabidaea triplinervia and Derivates. Biological and Pharmaceutical Bulletin, v.29, p.2307-2309, 2006.

MARIZ, S.R. et al. Possibilidades terapêuticas e risco toxicológico de Jatropha gossypiifolia L.: uma revisão narrativa. Revista Brasileira de Plantas Medicinais, v. 12, n. 3, p. 346-357, 2010.

MARTÍNEZ, M.A.D.P. et al. Flavonoid distribution in Tradescantia. Biochemical Systematics and Ecology, v. 21, n. 2, p. 255-265,1993.

MIRANDA, G.S. et al. Atividade antibacteriana in vitro de quatro espécies vegetais em diferentes graduações alcoólicas. Revista Brasileira de Plantas Medicinais, v.15, n.1, p. 104-111, 2013.

MOREIRA, R.R.D. et al. Composition and Activity against oral pathogens of the essential oil of Melampodium divaricatum (Rich.) DC. Chemistry \& Biodiversity, v.

Rev. Bras. PI. Med., Campinas, v.18, n.2, p.415-422, 2016. 
11, p. 438-444, 2014.

NCCLS. The National Committee for Clinical Laboratory Standards. The Methods for Dilution Antimicrobial Susceptibility Tests for Bacteria that Grow Aerobically; Approved Standard. $6^{a}$ ed. NCCLS document M7-A6. Wayne (PA): NCCLS; 2003, M07-a10.

NAKANO, V. et al. Virulence Markers and Antimicrobial Susceptibility of Bacteria of the Bacteroides fragilis Group Isolated from Stool of Children with Diarrhea in São Paulo, Brazil. Memórias do Instituto Oswaldo Cruz, v. 99, n. 3, p.307-312, 2004.

OLIVEIRA, K.A.M. et al. Atividade antimicrobiana e quantificação de flavonoides e fenóis totais em diferentes extratos de Própolis. Sêmina, v. 33, n. 2, p. 211-222, 2012.

OLIVEIRA, J.M. Núcleo de Estudos e Pesquisa em Fitoterapia, $\mathrm{dr}^{\mathrm{a}}$ Terezinha Rego. Memento Fitoterápico. $1^{\circ}$ Edição, Delta: São Luís, 2008, p.27.

OMS - ORGANIZAÇÃO MUNDIAL DA SAÚDE. Quality control methods for medicinal plants methods. $p$. 41-43, 1998, 122p.

OSORIO E, et al. Antiprotozoal and cytotoxic activities in vitro of Colombian Annonaceae. Journal of Ethnopharmacology, v. 111, p. 630-635, 2007.

PAULA, J.C. et al. Trypanocidal activity of organic extract from the Brasilian and Spanish marine sponges. Revista Brasileira de Farmacognosia, v. 25, p. 651-656, 2015.

PEREIRA, J.V. et al. Efeito antibacteriano e antiaderente in vitro do extrato da Punica granatum Linn. Sobre microrganismos do biofilme dental. Revista Brasileira de Farmacognosia, v.16, n.1, p. 88-93, 2006.

RASSI, A. Jr. et al. Chagas' disease. The Lancet, v. 375, n. 9723, p. 1388-1402, 2010.

RODRIGUES, J.H.S. et al. A quinoxaline derivative as a potente chemotherapeutic agente, alone or in combination with benzonidazole, against Trypanosoma cruzi. Plos One, v. 9, n.1, e85706, 2014.

RIOS, J.L. et al. Medicinal plants and antimicrobial activity. Journal Ethnopharmacology v.100, n.1-2, p.80-84, 2005

ROSA, R.L. et al. Investigação do uso de plantas medicinais no tratamento de indivíduos com diabetes melito na cidade de Herval D'Oeste - SC. Revista Brasileira de Plantas Medicinais, v. 14, n. 2, p. 306-
310,2012

SAVÓIA, E.J.L. Potencial de Tradescantia pallida cv. Purpurea para biomonitoramento da poluição aérea de Santo André - São Paulo, por meio do bioensaio Trad - MCN e do acúmulo foliar de elementos tóxicos. 2007. 102 p. Dissertação (Área de concentração: Fisiopatologia Experimental) Faculdade de Medicina da Universidade de São Paulo, USP, São Paulo.

SAMARÃO, S.S. et al. Estudo in vitro da atividade do extrato etanólico de sementes de bacupari (Rheedia gardneriana Planch. \& Triana) e das frações no crescimento de Streptococcus mutans. Revista Brasileira de Plantas Medicinais, v.12, n.2, p.234238, 2010.

SAMOILOVA, O.P. et al. Effects of light environment on the induction of chlorophyll fluorescence in leaves: A comparative study of Tradescantia species of different ecotyes. BioSystems, v. 105, p. 41-48, 2011.

SANTOS, K.K.A. et al. Avaliação da atividade antiTrypanosoma e anti-Leishmania de Mentha arvensis e Turnera ulmifolia. Boletín Latinoamericano y del Caribe de Plantas Medicinales y Aromáticas, v.11, n.2, p.147-153, 2012.

SAEIDNIA, S. et al. Two new monoterpene glycosides and trypanocidal terpenoids from Dracocephalum kotschyi. Biological and Pharmaceutical Bulletin, v.52, p.1249-1250, 2004.

SILVA, A.M.A.P. et al. Avaliação da atividade antimicrobiana da planta Tradescantia pallida Munt (Taboquinha Roxa). Revista Brasileira de Plantas Medicinais, v.17, n.3, p.374-378, 2015.

SOUSA, R.M.F. et al. Chemical composition, cytotoxic, and antibacterial activity of the essential oil from Eugenia calycina Cambess leaves against oral bactéria. Industrial Crops and Products, v. 65, p. 71-78, 2015.

TOLKE, E.E.A.D. et al. A família Commelinaceae Mirb. Em inselbergs do agreste paraibano. Revista de Biologia e Farmácia, v.5, n. 2, p. 1-10, 2011.

USHIMARU, P.I. et al. Antibacterial activity of medicinal plants. Brazilian Journal of Microbiology, v.38, n.4, p.717- 9, 2007

VIEGAS, E.C. et al. Toxicidade de óleos essenciais de alho e casca de canela contra fungos do grupo Aspergillus flavus. Revista Horticultura Brasileira, v.23, n.4, p.915-19, 2000. 